\title{
Quatro poemas de Thomas Mann
}

\author{
Augusto Rodrigues
}

Thomas Mann (1875-1955), grande romancista alemão do século XX, autor de, entre outros, Buddenbrooks [Os Buddenbrooks] (1901), Der Zauberberg [A Montanha Mágica] (1924) e Doktor Faustus [Doutor Fausto] (1947), escreveu também alguma poesia na juventude. Consciente, porém, da sua qualidade prosaica e até mesmo um tanto kitsch, como alguns críticos mais tarde a consideraram, nunca se empenhou mais seriamente nesta direção. Os poucos desses versos que restaram (outros foram perdidos) permanecem esparsos e avulsos, de modo que não chegam a formar uma obra poética.

Neste artigo serão apresentados três desses esforços em ordem cronológica: "Siehst Du, Kind, Ich Liebe Dich" [Veja Só, Criança, Eu Te Amo], “Unbetitelt” [Sem Título], "Monolog” [Monólogo], além de um poema que dedicou à sua esposa em 1939. Os comentários se limitarão a explicitar, sobretudo, algumas dificuldades que encontrei durante a tradução dos poemas.

Vejamos, pois, o primeiro, provavelmente de 1893: 
Augusto Rodrigues. Quatro poemas de Thomas Mann

\section{Siehst Du, Kind, Ich Liebe Dich}

Siehst du, Kind, ich liebe dich, da ist nichts zu machen; wollen halt ein Weilchen noch beide drüber lachen.

Aber einmal, unverhofft, kommen ernste Sachen,siehst du, Kind, ich liebe dich da ist nichts zu machen!

\section{Veja Só, Criança: Eu Te Amo}

Veja só, criança: eu te amo,

E não há como evitar

Que possamos, por um instante,

Disto nos regozijar.

De modo inesperado, porém,

Surgem coisas sérias no ar;

Veja só, criança: eu te amo,

E não há como evitar!

Nesse pequeno poema lírico, influenciado talvez pelo poeta alemão Heinrich Heine (1797-1856), o segundo verso oferece duas possibilidades de tradução: ou "aí não há o que fazer" ou "quanto a isso não há o que fazer" ("da ist nichts zu machen"). A possibilidade que escolhi é equivalente à segunda: "e não há como evitar". 
Optei por esta última por acreditar que "não há o que fazer" possa ser interpretado, neste caso, como "não há como evitar". Uma segunda razão seria a da rima que pretendia obter com a do quarto verso, que devia ser também no infinitivo para estar de acordo com o original "machen/lachen" (fazer/rir), ambos no infinitivo, mesmo que em português em geral se procure evitar rimas nessa forma nominal.

Uma das grandes dificuldades da tradução poética alemão/ português é a do número de sílabas de certos adjetivos ou advérbios em alemão, bastante curtos, que necessitam um desdobramento em português, que com freqüência tornam o verso muito mais longo. Por exemplo: "unverhofft" significa aqui "inesperadamente", ou ainda "de modo inesperado" (ambas muito mais longas), esta última sendo a solução que encontrei, por preferir evitar, em poesia, o emprego de advérbios em "mente" quando se pode desdobrá-los.

No caso do segundo verso da segunda estrofe, "kommen ernste Sachen", optei por traduzi-lo como "surgem coisas sérias no ar", com o intuito acima de tudo de preservar a rima rica de substantivo com verbo presente no original (Sachen/machen), e que ainda rimasse com as anteriores pobres (machen/lachen - evitar/regozijar).

O segundo poema, sem título, aparece no meio de Gefallen [Decaída], primeira novela mais longa de Thomas Mann, publicada na revista "Die Gesellschaft" de Leipzig em 1894, quando o autor contava 19 anos:

\section{[Unbetitelt]}

Wenn rings der Abendschein verglomm,

Der Tag sich still verlor,

Dann falte deine Hände fromm

Und schau zu Gott empor. 
Augusto Rodrigues. Quatro poemas de Thomas Mann

Ist's nicht, als Ruh' auf unserm Glück

Sein Auge wehmutsvoll,

Als sagte uns sein stiller Blick

Daß es einst sterben soll?

Daß einst, wenn dieser Lenz entschwand,

Ein öder Winter wird,

$\mathrm{Da}$ an des Lebens harter Hand

Eins von dem andern irrt? -

Nein, lehn dein Haupt, dein süßes Haupt

So angstvoll nicht an meins,

Noch lacht der Frühling unentlaubt

Voll lichten Sonnenscheins!

Nein, weine nicht! Fern schläft das Leid, O komm, o komm an mein Herz!

Noch blickt mit jubelnder Dankbarkeit

Die Liebe himmelwärts!

\section{[Sem Título]}

Quando a tarde cai, e então

O dia em silêncio termina, Junte as mãos em devoção,

E olhe a Deus acima.

Não estão seus olhos pesarosos,

Com pena de nossa alegria, 
Dizendo-nos silenciosos,

Que um dia ela morreria?

Que um dia, quando der lugar

A primavera a um ermo inverno,

Um do outro há de se distanciar

Na dura vida em vento eterno?

Não, não deites tua cabeça aqui

Na minha tão amedrontada,

A primavera ainda sorri

Na clara luz do sol banhada!

Não, não chores! Longe dorme a dor, -

Venhas, venhas a meu coração!

Pois, olhando ao céu, o amor

Ainda brilha com gratidão!

A principal dificuldade que enfrentei aqui foi diante dos versos curtos do alemão (de oito e seis sílabas). Se fosse traduzi-los de forma direta ou literal, ficariam muito longos em português. O primeiro verso é um bom exemplo deste problema: “Wenn rings der Abendschein verglomm", que, literalmente, significa: "Quando em volta o brilho da tarde se tiver apagado". Outro exemplo seria o primeiro verso da quarta estrofe: “Nein, lehn dein Haupt, dein süßes Haupt", "Não, [não] deites tua cabeça, tua doce cabeça" - também bastante comprido em português. "Haupt" tem uma sílaba, enquanto a sua tradução, "cabeça" (ou "cabecinha", numa forma mais íntima), tem três. Mesmo que não tenha tido a intenção de reproduzir a métrica do original (a fórmula 8/6-8/6), procurei manter um ritmo e uma musicalidade semelhantes, que não seriam atingíveis se os versos em português fossem demasiado longos. Tive então de procurar 
soluções mais breves com um léxico que preservasse, é claro, o máximo do conteúdo e da beleza lírica do poema. Como a minha prioridade, além do ritmo, era reproduzir as rimas alternadas do original, tive de levar também esse aspecto em consideração.

A terceira estrofe foi a que me ofereceu as maiores dificuldades, pois não encontrava solução para ela no tocante ao esquema de rimas sem ter de realizar diversas inversões: “Daß einst, wenn dieser Lenz entschwand / Ein öder Winter wird / Daß an des Lebens harter Hand / Eins von dem andern irrt?" Diretamente seria: "Que um dia, quando esta primavera desaparecer / virá um ermo inverno / que na dificuldade da vida / um do outro há de se separar?". Tendo em vista a reprodução das rimas alternadas, realizei algumas inversões que me tornaram essa disposição possível. "Em vento eterno" é algo que introduzi na tradução que não se encontra no original, não só por conta da rima com "inverno", mas antes como uma tentativa de acentuar o caráter sentimental do poema, representado aqui por meio de alusões à natureza (ao clima).

O terceiro poema apareceu pela primeira vez na mesma revista "Die Gesellschaft" de Leipzig, em 1899, quando Thomas Mann estava ainda ocupado com a composição de seu primeiro romance, Buddenbrooks, que seria publicado, com grande êxito, dois anos depois. Este poema, fortemente autobiográfico, dá uma idéia do caráter em formação do jovem autor: 


\section{Monolog}

Ich bin ein kindischer und schwacher Fant,

Und irrend schweift mein Blick in alle Runde,

Und schwankend fass' ich jede starke Hand.

Und dennoch regt die Hoffnung sich im Grunde,

Daß etwas, was ich dachte und empfand,

Mit Ruhm einst gehen wird von Mund zu Munde.

Schon klingt mein Name leise in das Land,

Schon nennt ihn mancher in des Beifalls Tone, -

Und Leute sind's von Urteil und Verstand.

Ein Traum von einer schmalen Lorbeerkrone

Scheucht oft den Schlaf mir, unruhvoll, zur Nacht,

Der meine Stirn einst zieren wird zum Lohne

Für dies und jenes, das ich gut gemacht. 
Augusto Rodrigues. Quatro poemas de Thomas Mann

\section{Monólogo}

O que sou é um singelo e fraco infante,

Cujo olhar vagueia em toda direção,

E que aperta as mãos fortes oscilante.

Sinto, porém, no fundo, a aspiração

De que algo do que pensei e senti

Vá um dia com fama de sala a salão.

Meu nome já se ouve aqui e ali-

Pessoas já o aplaudem no coração,

Discutem e compreendem o que escrevi.

Um sonho com uma bela coroa de louros

Não falha em tirar-me o sono, no breu,

Que me ornará a fronte em dias vindouros,

Por isto ou aquilo que se mostrou meu.

Aqui procurei reproduzir tanto o metro quanto o tom prosaico do original. Os seus pentâmetros iâmbicos transformei em algo próximo dos decassílabos portugueses, procurando utilizar um léxico de impacto semântico correspondente. Quanto à sua estrutura de rimas, a/b/a, b/a/b, a/c/a, c/d/c/d, optei por estabelecer uma disposição ligeiramente diversa na tradução $(\mathrm{a} / \mathrm{b} / \mathrm{a}, \mathrm{b} / \mathrm{c} / \mathrm{b}, \mathrm{c} / \mathrm{b} / \mathrm{c}, \mathrm{d} / \mathrm{e} / \mathrm{d} / \mathrm{e})$, de modo a facilitar uma reprodução que me pareceu mais direta do conteúdo.

Nesse poema fiz diversas adaptações, também tendo em vista o esquema de rimas. Tomemos a segunda estrofe, por exemplo: “Und dennoch regt die Hoffnung sich im Grunde / Daß etwas, was ich dachte und empfand / Mit Ruhm einst gehen wird von Mund zu Munde". Literalmente, seria: “E, no entanto, se faz sentir no fundo a 
esperança / Que algo que tenha pensado e sentido / Passe um dia com fama de boca em boca". Por conta do esquema de rimas que queria reproduzir, cheguei então às soluções finais: "Sinto, porém, no fundo, a aspiração / De que algo do que pensei e senti / Vá um dia com fama de sala a salão", que, ao mesmo tempo, preservam o sentido das idéias do original.

O mesmo se poderia dizer da terceira estrofe: "Schon klingt mein Name leise in das Land / Schon nennt ihn mancher in des Beifalls Tone, - / Und Leute sind's von Urteil und Verstand". "Meu nome já soa baixinho no país / Alguns já o mencionam em tom de aplauso / E há pessoas que o julgam e compreendem". Tendo em vista novamente a disposição das rimas, decidi fazer algumas adaptações que conduziram ao resultado final, mais adequado à estrutura que queria atingir.

$\mathrm{Na}$ quarta estrofe, minha prioridade era não só manter as rimas alternadas, mas também procurar obter duas rimas ricas, enquanto o original traz somente uma (Nacht/gemacht - substantivo/ verbo). Isso é algo que sempre procuro fazer quando traduzo poesia: preservar ao máximo as rimas ricas do original, e, se houver poucas, tentar obter, quando possível, um número maior ainda delas. "Quando possível" quer dizer: quando o conteúdo não é de nenhum modo prejudicado com isso. Com base nessa idéia, atingi a solução definitiva, com duas rimas ricas: louros/vindouros (substantivo/adjetivo) e breu/meu (substantivo/pronome).

O quarto e último poema que pretendo apresentar aqui foi escrito à mão no exemplar de Lotte in Weimar [Carlota em Weimar] (1939) que Thomas Mann dedicou à sua esposa, Katia Mann. Foi, porém, só em 1953, no discurso por ocasião do aniversário de 70 anos de Katia, que Mann tornou públicos estes que chamou naquele momento de "Privatverslein eines Prosaikers"1 ["versinhos particulares de um prosador"]:

Mann, Thomas. "Katia Mann zum siebzigsten Geburtstag". In: Über mich selbst Autobiographische Schriften. Frankfurt: Fischer, 1997, p. 181. 
Augusto Rodrigues. Quatro poemas de Thomas Mann

\section{[Unbetitelt]}

Angefangen an trautem Ort-

Schrieb in der Fremde daran fort.

Einmal fehlt' ich, macht's einmal gut-

Es wurde fertig in Deiner Hut.

Bleibe Du mir auf dieser Erden,

So soll alles fertig werden!

\section{[Sem Título]}

Dei início em local costumeiro-

Prossegui escrevendo no estrangeiro.

Às vezes falhei, às vezes acertei-

Mas, com seu apoio, terminei.

Fique ao meu lado neste lidar,

Que tudo eu hei de terminar!

O romance Lotte in Weimar foi iniciado ainda "an trautem Ort" ["em local costumeiro"], ou seja, na Europa de língua alemã - em Küsnacht, Suíça, em 1936 -, e teve de ser desenvolvido e concluído "in der Fremde" ["no estrangeiro"], em Princeton, Estados Unidos, em 1939, um ano depois que a família Mann emigrou da Europa e se estabeleceu no "Novo Mundo".

Como nestes versinhos não há uma métrica definida, respeitada ao longo deles todos, não me preocupei com isso. Em termos estruturais, procurei reproduzir somente as rimas emparelhadas do original. No caso do terceiro e quarto versos, porém, não pude manter suas rimas ricas, pois isso implicaria, a meu ver, uma alteração 
por demais extrema do seu significado simples e direto. Por essa razão, mantive a idéia do original: "Às vezes falhei, às vezes acertei- / Mas, com seu apoio, terminei". Para as outras rimas ricas encontrei equivalentes sem grandes dificuldades: costumeiro/estrangeiro (como substantivo) e lidar (como substantivo)/terminar.

No primeiro verso, "Angefangen an trautem Ort", há algo curioso. O termo "traut" é, na verdade, uma redução de "vertraut" [familiar, íntimo, algo que se conhece a fundo], realizada por Mann talvez em favor do comprimento do verso (que não devia ser longo). Na tradução, optei por "costumeiro", por conta da rima fácil com "estrangeiro" ("Fremde"). Numa outra concepção, pensei em alterar as duas rimas para "familiar" e "além-mar", formando então os versos: "Dei início em local familiar / Prossegui escrevendo no além-mar". "Além-mar", porém, não é exatamente o que Mann afirma no poema. Ele diz "Fremde", que significa "exterior" ou "estrangeiro", mas não necessariamente um exterior "além-mar" ou "ultramar". Apesar de saber, pela história de sua vida, que este é o caso, não é o que está no seu original.

Estes quatro poemas de Thomas Mann oferecem um exemplo do caráter esparso e avulso de sua poesia, que não permite que seja considerada como uma "obra poética". Eles atestam, porém, que Mann, assim como muitos outros grandes prosadores, também se ocupou com a poesia, sobretudo durante a adolescência. 